\title{
HYDROGEN ENHANCED THERMAL FATIGUE OF $\gamma$-TITANIUM ALUMINIDE
}

\author{
William Dunfee, Ming Gao, Robert P.Wei and William Wei* \\ Department of Mechanical Engineering and Mechanics \\ Lehigh University, Bethlehem, PA 18015, USA \\ * Universiteit Twente, Enschede, The Netherlands \\ formerly MTU Motoren- und- Turbinen- Union, Münich, Germany
}

(Received January 24,1995)

\section{Introduction}

The low density and attractive high-temperature characteristics of titanium aluminide intermetallics have placed them among the most promising new materials for use in intermediate and high temperature applications in future aircraft engines and hypersonic vehicles [1-3]. However, a major concern with these materials is their potential for embrittlement from high temperature oxidation or hydrogen exposure [1-8]. When considering the intended applications for titanium aluminides, it also becomes apparent that the materials will be subjected not only to deleterious environments, but to thermal cycling as well. It is therefore important to assess their ability to resist degradation through the combined actions of environment and thermal cycling.

Hydrogen and hydrogenous environments can severely embrittle many intermetallic compounds [9]. Limited experiments on gamma and gamma-based titanium aluminides have shown that the tensile stressstrain and fracture behavior of both single-phase and two-phase gamma titanium aluminide alloys can be degraded by hydrogen and hydrogenous gases at both ambient and elevated temperatures, primarily through a loss in ductility $[2,3,5-8]$. Little work, however, has been done on the combined actions of environment and thermal fatigue on the material.

A research program has thus been conducted in order to: (1) assess the ability of gamma-based titanium aluminide alloys to resist degradation by thermal cycling in hydrogen and hydrogenous environments, and (2) develop a scientific understanding of the mechanisms for failure under combined thermal cycling and environmental degradation. The results are briefly reported here.

\section{Experimental}

A two-phase gamma titanium aluminide with the nominal composition of $\mathrm{Ti}-48 \mathrm{Al}-2 \mathrm{Cr}$ (at. \%) was used in this study. The material was supplied by Motoren- und- Turbinen- Union of Germany in the form of a hot-isostatically-pressed (HIP-ed) $25 \times 50 \times 75 \mathrm{~mm}$ ingot with a two-zone casting microstructure, namely, a thin layer of chill zone and a well-developed columnar zone. The alloy had a deformed duplex $\left(\alpha_{2}+\gamma\right)$ microstructure consisting of regions of $\left(\alpha_{2}+\gamma\right)$ lamellar structure along with equiaxed gamma grains. Grain sizes ranged from 50 to $300 \mu \mathrm{m}$, Fig. 1 .

Specimens designed specifically for thermal fatigue testing were machined from the ingot of material using Electro-Discharge Machining (EDM) and polished to remove surface defects introduced by EDM. The 


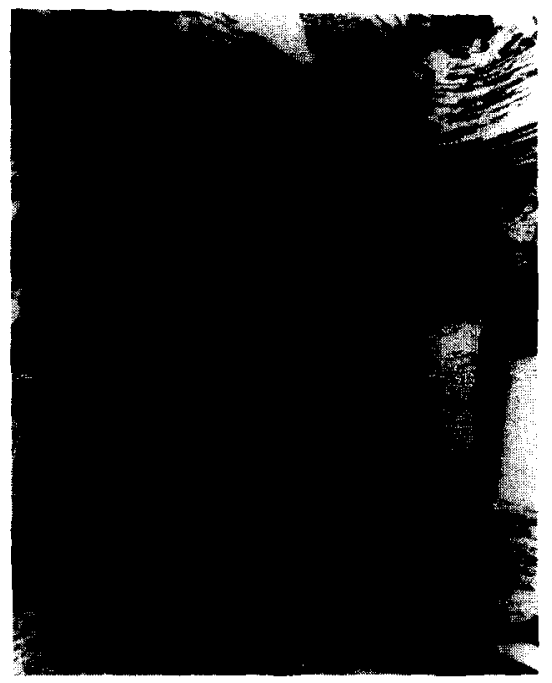

Figure 1. A typical optical micrograph showing a deformed duplex $\left(\alpha_{2}+\gamma\right)$ microstructure. (Polarized Illumination).

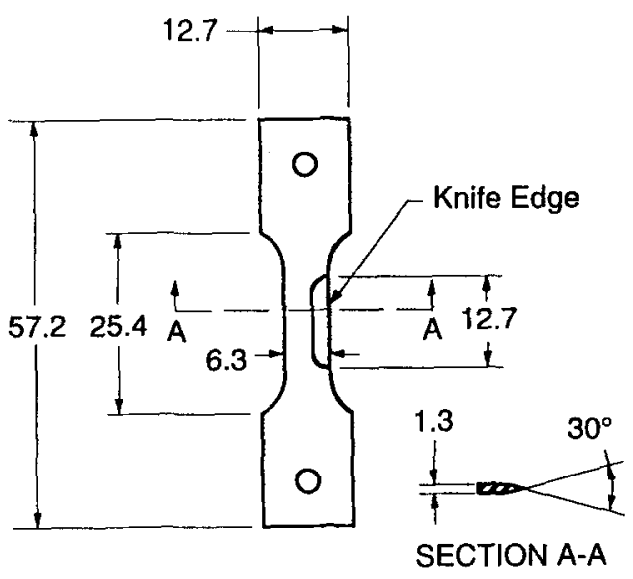

Dimensions in millimeters

Figure 2. A sketch of the specimen used for thermal cycling.

specimen design accounts for special environmental, thermal, and stress considerations. The specimens were thin and flat, with a $1.3 \mathrm{~mm}$ thick by $6.3 \mathrm{~mm}$ wide by $12.7 \mathrm{~mm}$ long gage length, Fig. 2. This geometry provides a high surface area-to-volume ratio to maximize the environmental exposure area for reaction, allows for rapid forced convective cooling, and ensures a uniform temperature distribution throughout the sample thickness. The specimen also has a sharp, wedge-shaped edge on one side to improve rapid cooling from a chilled gas jet, Fig. 2.

A test system and associated procedures were developed to perform environmentally assisted thermal fatigue with a preloaded fixed-grip condition on the test specimens. The test system used direct electrical resistance heating to rapidly heat the specimen and a chilled gas jet to provide swift cooling. Details of the test system are reported elsewhere $[9,10]$.

Testing was conducted in high purity hydrogen (99.99\%), and high purity helium (99.995\%) as an inert reference. The test system was purged with over 500 times its volume of hydrogen or helium prior to test initiation. The specimens were tested with a pre-stress of $241 \mathrm{MPa}$ ( $50 \%$ of room-temperature yield strength). Thermal cycling was performed between room temperature and either $750^{\circ} \mathrm{C}$ or $900^{\circ} \mathrm{C}$. Under this cycling, out-of-phase cyclic stresses were obtained, i.e., the maximum stress (241 MPa) occurred at the lowest temperature, and vice-versa $[9,10]$. Crack growth was monitored using a long focal length traveling microscope.

The microstructure of the alloy was characterized using a Zeiss Axiomat optical microscope operated at bright field and polarized illumination modes. The post-test examination of the specimens was conducted with an ETEC Autoscan scanning electron microscope (SEM), operated at both secondary electron imaging (SEI) and back-scattered electron imaging (BSI) modes at $20 \mathrm{kV}$ and a working distance of 19 to $25 \mathrm{~mm}$. Of particular interest was the identification of features of the fracture surface morphology, including analyses of mating fracture surfaces, and information on the relationship between crack paths and microstructure.

\section{Results}

The number of cycles to failure and general features of failure varied greatly between helium and hydrogen environments. Table 1 details the lifetime results for all tests. No failures were observed for samples tested 
TABLE 1

Thermal Fatigue Lives (Cycles) in Helium and Hydrogen

\begin{tabular}{|c|c|c|}
\hline $\begin{array}{c}\text { Temperature } \\
\text { Cycling Range }\end{array}$ & Helium & Hydrogen \\
\hline & $>4,100$ & 3 \\
& $>4,145$ & 10 \\
$25-900^{\circ} \mathrm{C}$ & $>4,164$ & 11 \\
& $>4,626$ & 24 \\
& $<6,467$ & 30 \\
\hline & & 36 \\
& & 46 \\
& & 1,828 \\
& $>4,108$ & $>1,430$ \\
& $>4,230$ & $>3,000$ \\
\hline
\end{tabular}

(The symbol ">" stands for tests terminated at the indicated cycle numbers without failure)

in helium (inert environment) for over 4,000 cycles at either 750 or $900^{\circ} \mathrm{C}$. A few surface cracks were seen on these specimens after testing. For example, one specimen (tested at $900^{\circ} \mathrm{C}$ for $4,100 \mathrm{cycles}$ ) showed one small surface crack (approximately $1 \mathrm{~mm}$ long) perpendicular to the loading direction and several finer cracks (about $100 \mu \mathrm{m}$ long), Fig. 3. These cracks propagated from grain to grain without appreciable change in direction. The cracking in helium thus appeared to be unrelated to the microstructure and purely mechanical in nature.

The results obtained from testing in hydrogen were significantly different from those in helium. At $900^{\circ} \mathrm{C}$, none of the five specimens tested survived beyond 30 cycles, Table 1 . Failure by thermal cycling in hydrogen was brittle, with flat fracture surfaces perpendicular to the loading axis and the near absence of plastic deformation. Further examination revealed extensive zig-zag-shaped surface cracks with numerous branching over the entire gage length, Fig. 4. Some grains at the specimen surface had actually fallen out. This extensive damage, not seen on the specimens cycled in helium, indicates a strong attack on the material by hydrogen.

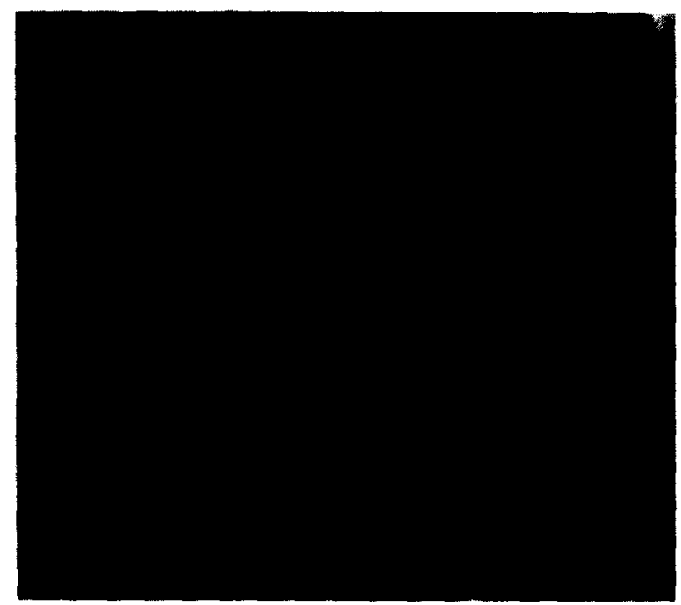

Figure 3. Surface cracks on a specimen cycled in helium to $900^{\circ} \mathrm{C}$. Test duration: 4100 cycles with no failure. (BSI)

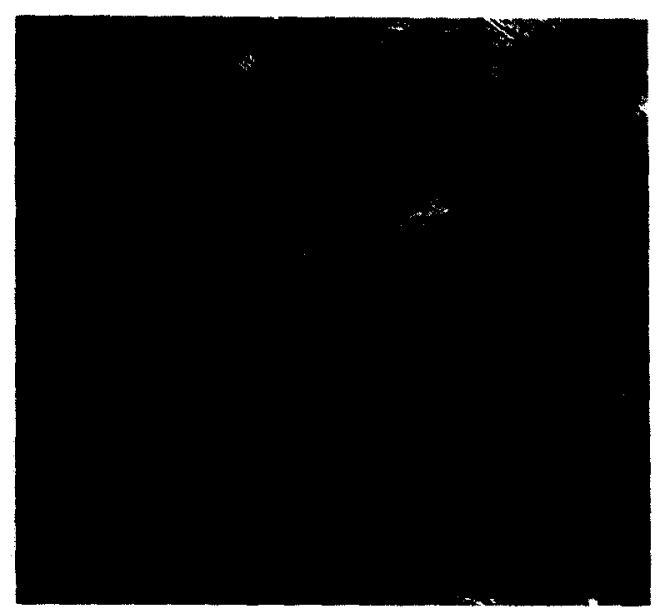

Figure 4. Surface cracks on a specimen cycled in hydrogen to $900^{\circ} \mathrm{C}$. Lifetime: 3 cycles. (BSI) 
Three distinct crack paths were identified [10]. These were (1) delamination along the $\alpha_{2} / \gamma$ interfaces in the lamellar structure, with some translamellar cracking (i.e., transverse to the lamellar plates), (2) cleavage cracking through the $\gamma$ grains along what appear to be crystallographic planes, and (3) cracking along grain boundaries, either between $\gamma$ grains, or between adjacent lamellar colonies, or between $\gamma$ grains and lamellar colonies. This preference for specific microstructural sites was responsible for the zig-zag-shaped crack paths on a microscopic scale, with the microstructural sites appearing to be the primary locations for hydrogen embrittlement.

The macroscopic features of the fracture surface morphology (FSM) were different from those of typical fatigue. There were no distinct crack initiation, propagation and rapid fracture zones. This implies that fracture by thermal cycling in hydrogen at $900^{\circ} \mathrm{C}$ was a multiple crack-initiation-and-growth process, rather than the result of the growth of a single crack. Detailed examinations at higher magnifications showed no visible fracture surface oxidation.

At $750^{\circ} \mathrm{C}$, samples that failed in hydrogen had two distinct lifetimes: under 50 cycles and above 1,400 cycles, Table 1. For those with lifetimes under 50 cycles, extensive surface cracking and attack (similar to those seen at $900^{\circ} \mathrm{C}$ ) were observed, Fig. 5a. However, only crack traces and limited surface attack could be identified on the other specimens, Fig. $5 \mathrm{~b}$. In-situ observations showed that multiple zig-zag-shaped surface cracks always formed and developed during the first 30 cycles of testing. But, unless the specimen fractured, this crack growth slowed and nearly stopped by about the 40th or 50th cycle, and a thin layer of surface oxide could be observed by eye. These observations indicate that the system was contaminated with oxygen, either from the hydrogen source itself, or from residuals (oxygen and water vapor) retained in the environmental chamber.

The FSM features of the specimens that fractured in under 50 cycles were nearly identical to those produced at $900^{\circ} \mathrm{C}$. A distinct three-zone feature, however, may be seen in the specimen fractured in 1,828 cycles, Figs. $6 \mathrm{a}$ and $6 \mathrm{~b}$, implying that fracture had resulted from the growth of a single, main crack. The crack was seen to initiate at one side of the specimen, then to propagate semi-circularly to form a relatively flat propagation zone, Figs. $6 \mathrm{a}$ and $6 \mathrm{~b}$. Oxidation of the fracture surfaces can be clearly seen in Fig. $6 \mathrm{c}$. The difference in FSM between these two fracture conditions suggests that different mechanisms were at work.

\section{Discussion}

The results of this study show that hydrogen has a significant effect on the thermal fatigue behavior of the gamma based alloy tested. The observations related to the large scatter in the data at $750^{\circ} \mathrm{C}$ suggested a
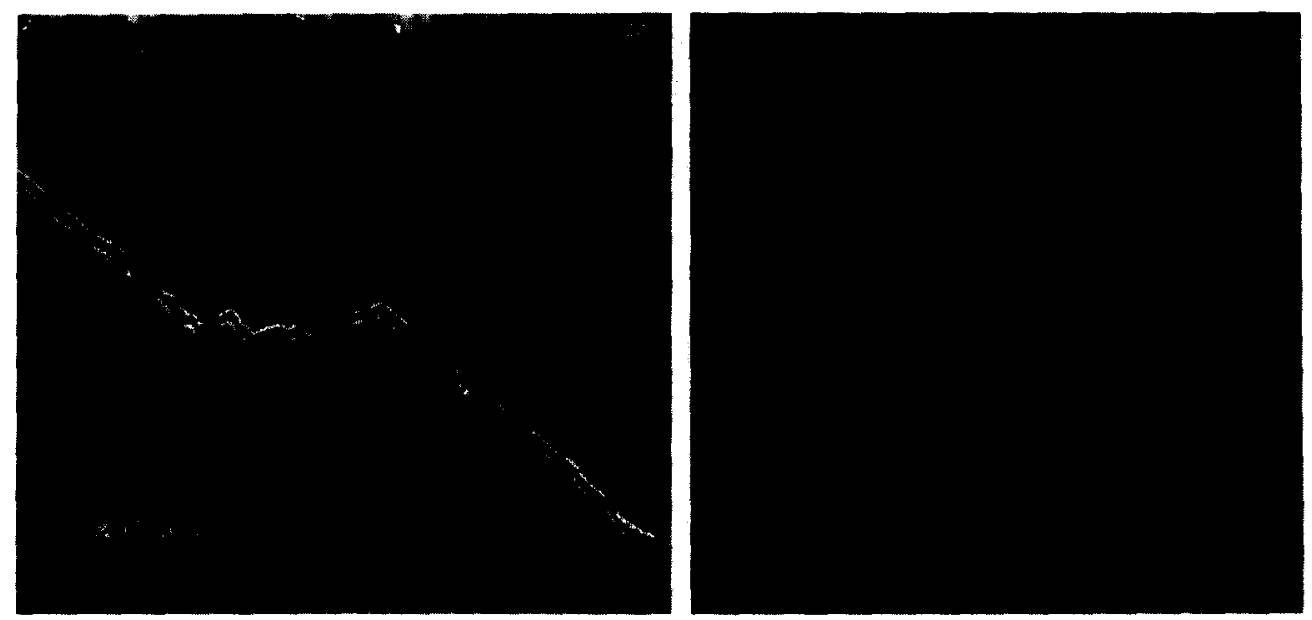

Figure S. Secondary cracks on specimens cycled in hydrogen to $750^{\circ} \mathrm{C}$ : (a) Lifetime: 46 cycles; (b) Test stopped at 200 cycles (no failure). (SEI) 

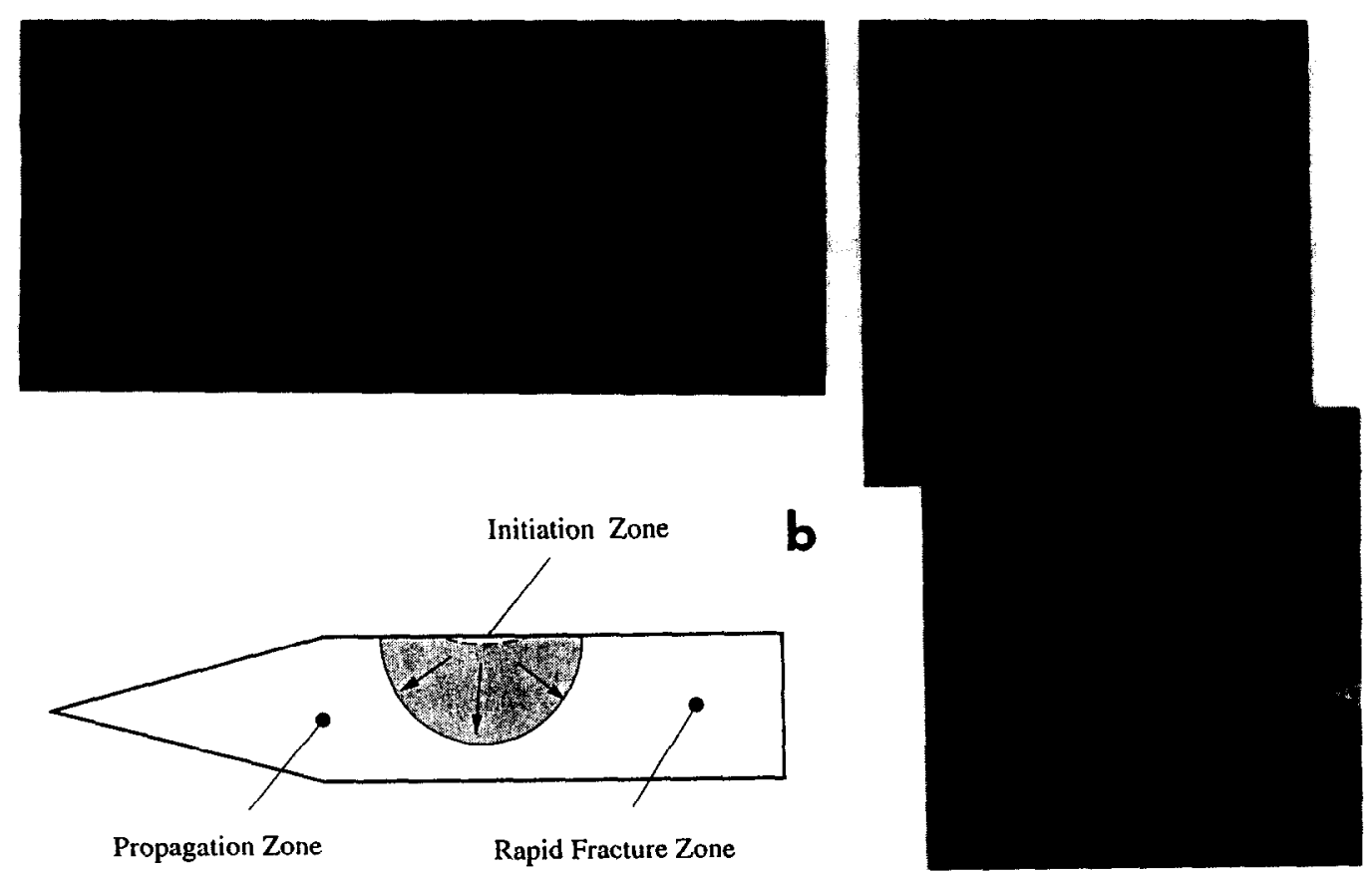

Figure 6. FSM produced by thermal cycling in hydrogen between 25 and $750^{\circ} \mathrm{C}$ : (a) SEM micrograph of mating fracture surfaces, (b) sketch of (a), and (c) SEM image of Area A in (a), showing a three-zone feature and heavy oxidation of the initiatiion and early propagation zone (seee Arrow 1). Lifetime: 1,828 cycles.

competition between hydrogen attack and surface oxidation. The hydrogen generates numerous cracks and assists in their growth by attacking and embrittling specific microstructures. However, at the same time, residual oxygen reacting with the alloy begins to form an oxide layer on the surface. Whether or not the specimen fails quickly depends upon which process dominates. This, in turn, depends upon the temperature and the residual oxygen level.

At temperatures above $800^{\circ} \mathrm{C}$, the rates of hydrogen absorption and diffusion are expected to be fast. The primary oxide which forms on the surface, $\mathrm{TiO}_{2}$-type, is porous and does not block the hydrogen from entering and reacting with the material $[2,14]$. Thus, rapid material failure is expected. At temperatures below $800^{\circ} \mathrm{C}$, the hy-drogen absorption and diffusion rates can be expected to be slower, and the residual oxygen begins forming a protective layer of $\mathrm{Al}_{2} \mathrm{O}_{3}$ on the surface [2,14]. If the concentration of residual oxygen is high enough, the oxide will succeed in covering the surface absorption sites quickly, preventing further hydrogen attack. The alloy then suffers mainly from oxidation and oxidation-enhanced cracking, and failure results from the slow growth of a single, main crack, as seen in thermal cycling in air [13], with a dramatically increased thermal fatigue life span. If the residual oxygen is low, oxidation of the surface would not be completed in time to obstruct hydrogen attack and prevent hydrogen-induced failure. Therefore, the widely varying lifetime results obtained during the $750^{\circ} \mathrm{C}$ testing in hydrogen can be explained by the competition between hydrogen attack and oxidation. The concentration of residual oxygen required to form a protective oxide for preventing hydrogen-induced failure has not yet been determined, but it is expected to be relatively low for gamma-based titanium aluminides [15]. Further work is needed to clarify the issue of the competition between oxidation and hydrogen attack.

\section{Summary}

A study of hydrogen enhanced thermal fatigue cracking was carried out for a gamma-based $\mathrm{Ti}-48 \mathrm{Al}-2 \mathrm{Cr}$ alloy by cycling between room temperature and 750 or $900^{\circ} \mathrm{C}$. The results showed that hydrogen can severely 
attack the gamma alloy, with resulting lifetimes as low as three cycles, while no failures were observed in helium for test durations of over 4000 cycles. The severity of hydrogen attack strongly depends on the upper limit of the temperature cycled and the cleanliness of the hydrogen. Specifically, the large scatter of life times at $750^{\circ} \mathrm{C}$ (ranging from 36 to more than 3000 cycles) have resulted from the competition between surface oxidation and hydrogen attack. The results suggest that an understanding of the combined actions of thermal cycling and hydrogen degradation is needed for assessing materials for high temperature applications in hydrogen.

\section{Acknowledgment}

The authors would like to thank MTU Motoren- und- Turbinen- Union of Germany for their support of this research.

\section{Reforences}

1. H. A. Lipsitt, High Temperature Ordered Intermetallic Alloys, 39, pp. 351-364, Materials Research Society, (1985).

2. F. H. Froes, C. Suryanarayana and D. Eliezer, Journal of Materials Science, 27 (19), $5113-5134$ (1992).

3. Y-W. Kim, Joumal of Metals, 41 (7), 24-30 (1989).

4. K. S. Chan and Y-W. Kim, Metallurgical Transactions, 23A, 1663-1677 (1992).

5. M. Nakamura, K. Hashimoto and T. Tsujimoto, Journal of Materials Research, 8 (1), $68-77$ (1993).

6. K. S. Chan and Y-W. Kim, Metallurgical Transactions, 24A, 113-125 (1993).

7. C. T. Liu and Y-W. Kim, Scripta Metallurgica et Materialia, 27, 599-603 (1992).

8. T. Takasugi and S. Hanada, Jourmal of Materials Research, 7, 2739-2745 (1992).

9. N. Stoloff, M. Shea and A. Castagna, Environmental Effects on Advanced Materials, pp. 3-19, Warrendale, PA: The Metallurgical Society (1991).

10. M. Gao, W. Dunfee, R. P. Wei and W. Wei, Fatigue and Fracture of Ordered Intermetallic Materials I, eds., W. O . Soboyejo, T. S. Srivatsan and D. L. Davidson, pp. 225-237, Warrendale, PA: The Metallurgical Society (1994).

11. M. Gao, W. Dunfee, R. P. Wei and W. Wei, submitted to ASTM Second Symposium on Thermo-Mechanical Fatigue Behavior of Materials, Phoenix, AZ (1994).

12. W. Dunfee, Master of Science Thesis, Lehigh University, Bethlehem, PA (1994).

13. M. Gao, W. Dunfee, R. P. Wei and W. Wei, submitted to TMS Symposium on Fatigue and Fracture of Ordered Intermetallic Materials II, Chicago, IL (1994).

14. Y. Umakoshi, M. Yamaguchi, T. Sakagami and T. Yamane, Journal of Materials Science, 24, 1599-1603 (1989).

15. J. B. Boodey, M. Gao and R. P. Wei, Environmental Effects on Advanced Materials, eds., Russell H. Jones and Richard E. Ricker, pp. 57-65, Warrendale, PA: The Metallurgical Society (1991). 